\title{
Time-Lapse Cleavage Rating Predicts Human Embryo Viability
}

\author{
D. HLINKA ${ }^{1}$, B. KALATOVÁ ${ }^{2}$, I. UHRINOVÁ ${ }^{2}$, S. DOLINSKÁ ${ }^{2}$, J. RUTAROVÁ $^{3}$, \\ J. ŘEZÁČOVÁ ${ }^{3}$, S. LAZAROVSKÁ ${ }^{1}$, M. DUDÁŚ ${ }^{2}$
}

${ }^{1}$ Prague Fertility Centre, Prague, Czech Republic, ${ }^{2}$ Fetal Medicine Program, Department of Cell Biology, Safarik University, Kosice, Slovakia, ${ }^{3}$ Institute for Care of Mother and Child, Prague, Czech Republic

Received November 15, 2011

Accepted May 18, 2012

On-line August 8, 2012

\section{Summary}

Chronology of three consecutive mitotic events in human preimplantation embryos was examined by time-lapse imaging. In zygotes producing well-formed and pregnancy-yielding expanded blastocysts, uniform time-patterning of cleavage clusters (c) and interphases (i) was revealed: $\mathrm{i} 2=11 \pm 1, \mathrm{i} 3=15 \pm 1, \mathrm{i} 4=23 \pm 1 \mathrm{~h} /$ $c 2=15 \pm 5, c 3=40 \pm 10, c 4=55 \pm 15$ min. Oppositely, shortened or prolonged durations of one or more cell cycles were strongly predictive of poor implantation and development. Furthermore, trichotomic mitosis was discovered in $17 \%$ of cases - zygotes cleaved into 3 blastomeres and 2-cell embryos into 5-6 cells (instead of normal 2 and 4). During conventional clinical assessment, such embryos are indistinguishable from normal, often considered just-in-course of the next cell cycle. Only detailed time-lapse monitoring paced at 10-minute intervals had proven all these embryos to be absolutely unviable, even in rare cases when they reduced their hypercellularity to normal cell counts via cell-cell fusion. Overall, we demonstrate that timelapse embryo cleavage rating (ECR) as a standalone diagnostic procedure allows for effective identification of viable early embryos with $90 \%$ specificity, while elimination of good-looking but unviable embryos can be assumed with a specificity of $100 \%$. Thus, making this non-invasive and contactless approach worth of addition to routine embryo screening in clinical IVF programs.

\section{Key words}

Time-lapse imaging in human embryos • Cell cycle analysis • Trichotomic / Tripolar mitosis - Selection for single-embryo transfer - Preimplantation screening and diagnosis - Clinical cytometry and morphometry

\section{Corresponding author}

Marek Dudas, Fetal Medicine Program, Department of Cell Biology, Safarik University, Moyzesova 11, SK-04001 Kosice, Slovak Republic. Fax: +421-55-6222-124. E-mail: marek.dudas.sk@gmail.com

\section{Introduction}

Reliable signs of embryonic fitness and accurate criteria for early embryo assessment after in vitro fertilization (IVF) are on high demand and are extensively elaborated starting from the oocyte stage and ending with blastocysts (Beuchat et al. 2008, Ebner et al. 2003, Gardner et al. 1998, Garello et al. 1999, Gianaroli et al. 2003, Murber et al. 2009, Kilani et al. 2009, Scott et al. 2007). To select the best embryo(s) to be transferred into the uterus, leading fertility clinics also use the additional classification criteria based on preimplantation genetic diagnosis, implemented either as routine screening or tailored to case-specific circumstances (Basille et al. 2009, Hlinka et al. 2001). Unfortunately, human early embryos show high frequency of genetic mosaicism, i.e. different chromosome complements in individual cells, thus setting a definitive technical limitation to all methods based on blastomere biopsy (Shahine and Cedars 2006, Los et al. 2004, Hlinka et al. 2001). Furthermore, additional factors such as redistribution of the oocyte transcriptome (RNA), ooplasmic pool, cytoskeletal (non)uniformity, metabolic health, uneven or patterned organelle distribution (Van Blerkom 2002), and de novo gene mutations, cannot be effectively addressed in single-cell diagnostics 
(Hernandez 2009). Thus, holistic diagnostic approaches would be beneficial, similar to complex fetal diagnosis in prenatal screening (Dankovcik et al. 2005); and therefore, separately from or in addition to single-cell genetic tests, whole-embryo morphological scoring schemes are often used, worldwide. The most usual evaluation of morphological parameters is based on daily microscopic observations. However, this classical approach can only reveal limited and static information (Meseguer et al. 2011), omitting the dynamics and exact timing of early mitotic divisions. Here we analyze the chronology of early mitotic events by continuous human embryo monitoring, demonstrating a strong correlation of the cell cycle timing and cleavage synchrony with the outcomes of pregnancy tests.

\section{Materials and Methods}

\section{Ethical considerations}

All embryos were conceived in a routine clinical IVF program certified and monitored by governmental authorities. All data were collected under informed consent, patient information protection, data-handling, in vitro diagnostics device operation, and good laboratory practice policies and/or certifications, and after the review and approval by the institutional Ethical Committee.

\section{Embryos}

All proband embryos resulted from the ICSI fertilization technique, following after standard ovarian stimulation protocols, transvaginal oocyte aspiration, and routine semen preparation. Only successful concepts (assessed as 2-pronuclear embryos after ICSI) were selected for further observations. Embryos were scored as morphologically normal when no pathologies were identified according to the consensus criteria (Magli et al. 2007); all other embryos were collectively named as bearing morphological anomalies for the purposes of this study. No specific groups of embryonic morphology, biological parents or their respective infertility treatments, embryo culture conditions, or other laboratory or medical treatment procedures were specifically selected for this study.

\section{Time-lapse monitoring}

A total of 180 embryos were subjected to automated time-lapse monitoring (PrimoVision, CryoInnovation Ltd., Hungary, 1 picture/10 min, intermittent white-light illumination) under standard cultivation conditions $\left(37.0^{\circ} \mathrm{C}, 5 \% \mathrm{CO}_{2}\right.$ in humid air).

\section{Scoring of embryonic cell cycles}

Image sequences were digitally recorded, then scored by human means; the exact timings of the three interphases and cleavages occurring after the two-cell stage were identified in automated records and then manually recorded in tables. Early embryonic development recorded in time-lapse regime is composed of alternating resting periods - interphases (i) and periods of mitotic activity - cleavages (c). Since two or more blastomeres were present in each observed embryo, and since all cells may not be absolutely synchronized in their cell cycles, it is not possible to truly observe the "interphase of the entire embryo" or the "cleavage of the entire embryo". To address these issues, an arbitrary cell cycle scoring system was developed with the following formal approximation (see Table 1, Fig. 2):

Approximated embryonic interphase cluster (AEIC, abbreviated to "i" in data sets and labels), or the interphase interval. In simple words, this scoring period can be defined as the initial portion of the cell cycle, where the interphases of individual embryonic blastomeres are clustered in their occurrence, technically measured as: The end-of-cleavage till end-of-cleavage interval, measured in two adjacent cell cycles, and selectively just in the last-cleaving (slowest) blastomere of one cycle and the first-cleaving (fastest) blastomere of the next cell cycle. For more details and further comprehension, see Figs 2 and 4, and Discussion.

Approximated embryonic cleavage cluster (AECC, abbreviated to "c" in data sets and labels), or the cleavage interval, is the scoring period defined as the end phase of the cell cycle, where the mitoses of individual embryonic blastomeres are clustered in their occurrence. Each cleavage interval occurs immediately after the respective interphase interval, thus forming together one full cell cycle. Technically, each AECC was measured as: The end-of-cleavage till end-of-cleavage interval, measured at the end of a given cell cycle, selectively from the end of cleavage of the first-cleaving (fastest) blastomere till the end of cleavage of the last-cleaving (slowest) blastomere of that cell cycle. For more details and further comprehension, see Figs 2 and 4, and Discussion.

\section{Embryo transfer and pregnancy scoring}

After 5 days of culture, the morphologically best 
blastocysts with distinct embryoblasts were transferred into the uterus (single embryo transfer), and the above defined data on duration of interphases and cleavages were correlated with the outcomes of pregnancy tests (fetal heart beat).

\section{Statistical grouping and tests}

To address the diagnostic value of time-lapse embryo cleavage rating, we have statistically evaluated the discrimination power of cleavage timeliness in relation to all basic morphometric and functional markers. All embryos were assigned their respective values for a combination of all descriptors - cleavage timeliness (derived recursively by normalization from the resulting data; see Table 1), blastocyst formation, pregnancy yield together with their diagnostic group rank (true or false positives or negatives, derived accordingly for each descriptor taken in the focus). Selectivity tests of relevant diagnostic aspects were calculated using convention formulas for sensitivity (SE) and specificity (SP), with variables derived from the corresponding 2-dimensional data matrices being centered each on a single particular descriptor (Tables 2-4).

\section{Results}

From a total of 180 pronuclear embryos, $114(63.3 \%)$ formed morphologically well-developed blastocysts, resulting in 28 clinical pregnancies (Fig. 1).

\section{Normal cell cycle durations}

Durations of approximated interphases and cleavages of a subset of pregnancy-yielding blastocysts were averaged, and were considered to be the empirically determined normal cleavage pattern for this study. Embryos with all time periods fitting within these normal values (Table 1) were designed $\mathrm{T}$ (timely cleaving), while all other embryos with any number and any directionality of time deviations were designed as $U$ (untimely cleaving). This terminology is used hereinafter in the text and figures.

\begin{tabular}{|l|c|c|c|}
\hline $\begin{array}{l}\text { Cleavage } \\
\text { timeliness: }\end{array}$ & $\begin{array}{c}\text { Timely } \\
\text { (T) }\end{array}$ & $\begin{array}{c}\text { Untimely } \\
\text { (U) }\end{array}$ & Total \\
\hline $\begin{array}{l}\text { (A) Abnormalities } \\
\text { in morphology }\end{array}$ & $\mathbf{1 4}$ & $\mathbf{5 2}$ & 66 \\
\hline $\begin{array}{l}(\mathrm{4}) \text { Blastocysts, } \\
\text { no pregnancy }\end{array}$ & $\mathbf{7 8}$ & $(28.9 \%)$ & $(36.7 \%)$ \\
\hline $\begin{array}{l}\text { (BP) Blastocysts } \\
\text { giving pregnancy }\end{array}$ & $\mathbf{2 8}$ & 86 \\
\hline Total & $15.6 \%)$ & $(4.4 \%)$ & $(47.7 \%)$ \\
\hline
\end{tabular}

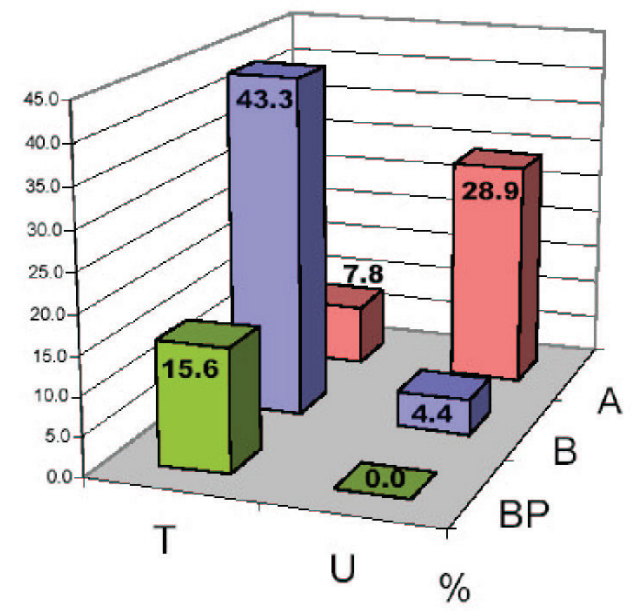

Fig. 1. Counts and percentage ratios of embryos in relation to their cleavage (un)timeliness, morphology, and uterine nidation success.

Table 1. Durations of approximated interphases (i) and approximated cleavages (c) in nidation-competent human embryos. Please refer to Fig. 2 and Fig. 4 for correlation of these numeric values with embryonic cleavage stages and corresponding normal morphologies.

\begin{tabular}{lcccccc}
\hline & i2 & c2 & i3 & c3 & i4 & c4 \\
\hline Period & interphase 2 & cleavage 2 & interphase 3 & cleavage 3 & interphase 4 & cleavage 4 \\
Definition & 2 cells & 3 to 4 cells & 4 cells & 5 to 8 cells & 8 cells & 9 to 16 cells \\
Duration & $11 \pm 1$ & $15 \pm 5$ & $15 \pm 1$ & $40 \pm 10$ & $23 \pm 1$ & $55 \pm 15$ \\
Time unit & $\mathrm{h}$ & min & $\mathrm{h}$ & min & $\mathrm{h}$ & min \\
\hline
\end{tabular}



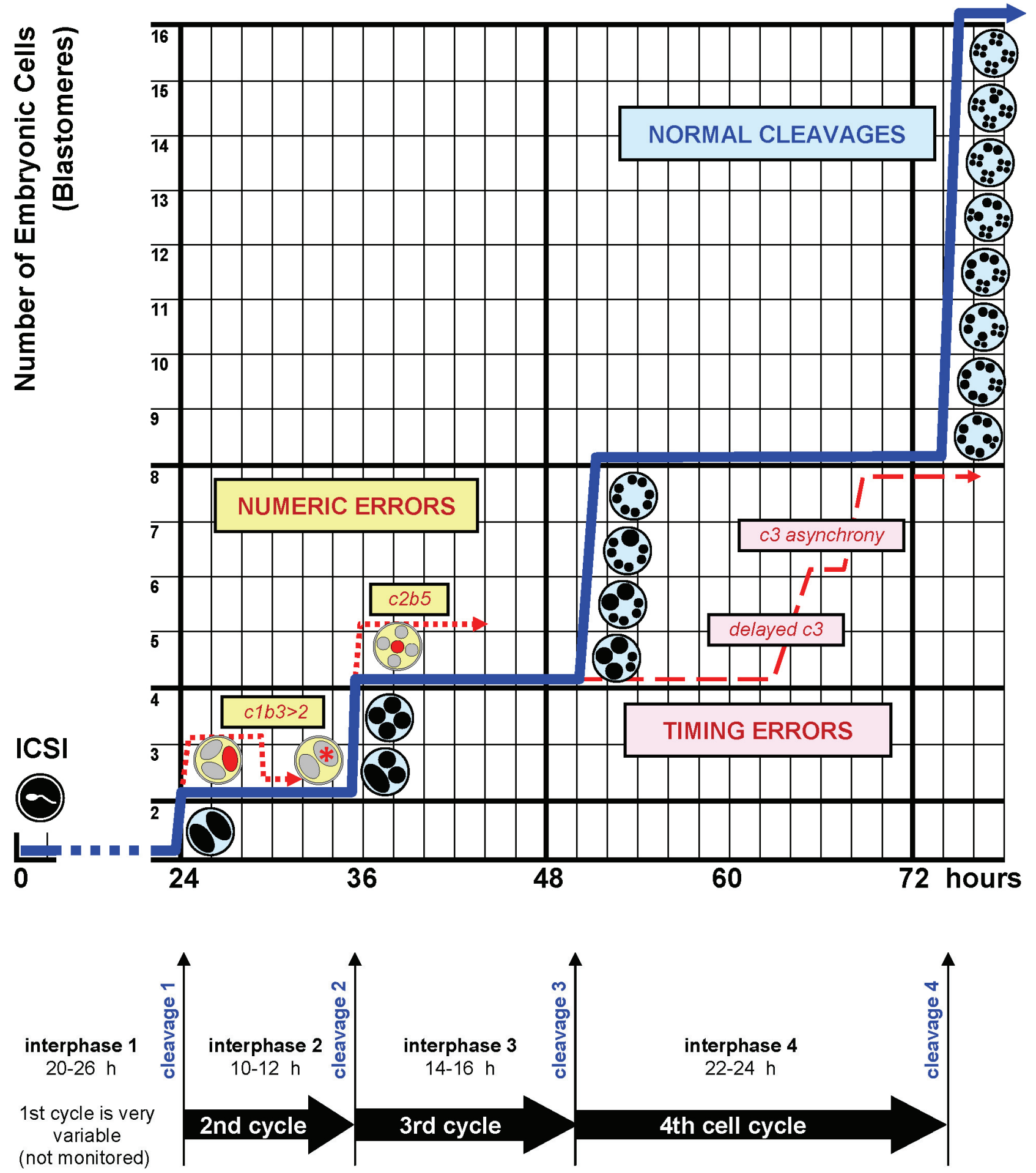

Fig. 2. Cleavage grafikon. Counts of cells (axis $Y$ ) are recorded for each moment (time step) of time-lapse imaging (axis $X$ ). Embryos are schematized as circles, with enclosed spots representing blastomeres. When embryos cleave, the number of spots increases and the grafikon curve is rising, while interphases of individual cell cycles create characteristic plateaus. Normally, cleavages of each cell cycle occur synchronously, i.e., nearly at the same time (cleavage clusters, seen as occasional sudden curve rises in the grafikon). Curves rising above the normal solid blue curve indicates mitoses with too many daughter cells (dotted red line; c2b5 is an example with 5 blastomeres resulting from cleavage $2 ; c 1 b 3>2$ means 3 blastomeres after cleavage 1 followed by cell fusion reducing the cell number to 2 / see Fig. 3). Long plateaus (dashed red line) indicate prolonged interphases, i.e., delayed cleavages. When one or more noticeable plateaus are interpositioned within the curve rise, asynchronous cleavage of sister blastomeres occurred; example is shown during cleavage 3 (c3). 
Abnormal embryos are predominant after untimely cleavages

Intriguingly, $52(78.8 \%)$ of a total of 66 abnormal embryos occurred in the group of untimely cleaving embryos, while only $14(21.2 \%)$ of them appeared among timely cleaving embryos. From the timing aspect, a total of 60 untimely cleaving embryos produced $52(86.6 \%)$ abnormally shaped embryos, while timely cleavages yielded only 14 (11.6\%) abnormities out of 120 embryos. These results suggest that morphological anomalies in early embryos are strongly associated with errors in duration of the cell cycle. While timing errors do occur in the early three cell cycles (2nd to 4th), the morphological anomalies may occur either concurrently, or subsequently at late blastocyst stages, or both (images not shown).

Timely cleavages associate with superior blastocyst development

Another striking difference between timely and untimely cleaving embryos was in the rate of blastocyst development: $88.3 \%$ versus $13.3 \%$, respectively. Considering (i) this positive association between untimely cleavages and the low blastocyst yields, together with (ii) the above demonstrated association between untimely cleavages and high morphological abnormality rates, our results prove that untimely cleavage correlates with pronouncedly poor quality of embryonic development. And vice versa, normal cleavage timing resulted in superior staging and morphology.

Morphologically identical blastocysts are not functionally equal

On the other side, the ability to yield blastocysts was a common feature shared by both embryonic groups (timely and untimely cleaving). However, based on the above associations between cleavage timing and morphology, we have questioned whether the blastocysts resulting from untimely cleaving embryos are functionally equal to the morphologically equal blastocysts resulting from timely cleaving embryos. Matching of morphometric data with pregnancy records had revealed that while 28 of 106 timely cleaving blastocysts underwent a successful nidation, the implantation rate in the untimely group was zero. These results definitely suggest that errors in timing of early cleavages are a detrimental mark of poor embryonic development and post-implantation non-viability.

Transitory, disappearing anomalies detected in timelapse records

Detailed analysis of morphogenesis in 10-minute steps revealed numeric cleavage anomalies present exclusively in the group of untimely cleaving embryos. Surplus blastomeres appeared in some embryos at the end of $1 \mathrm{st}$ or 2 nd cell cycle, resulting in 3 or 5 blastomeres instead of normal 2 or 4 , respectively (Fig. 3b). While some of the latter embryos yielded blastocysts, $0 \%$ out of 18 zygotes cleaving into 3 blastomeres reached the blastocyst stage. Moreover, some of the surplus blastomeres disappeared, apparently by cell-cell fusion (Fig. 3b-d), resulting in morphologically normal embryos. These observations further underline the importance of a detailed, frequently sampled time-lapse imaging in embryonic health assessment, especially if early embryo transfer is planned and late embryonic morphology would not therefore be performed. Timelapse-based embryonic cleavage scoring (ECR) is capable of excluding good-looking but developmentally incompetent early embryos from intrauterine transfer.
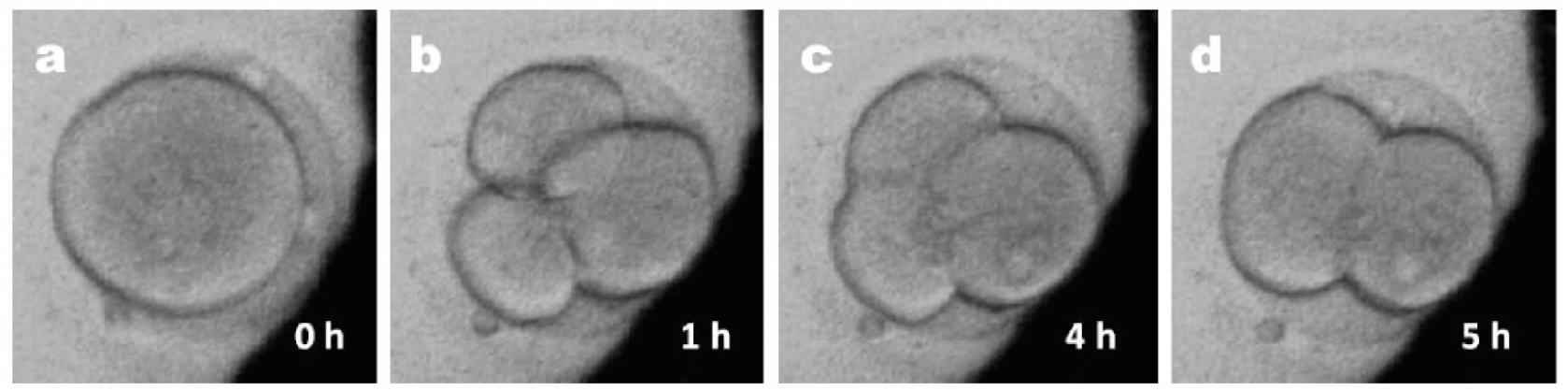

Fig. 3. Time-lapse series of photographs showing a zygote (a) cleaving abnormally into 3 blastomeres (b). Two of them subsequently fuse together (c-d), resulting in morphologically normal 2-cell embryo (d) that would be routinely scored as viable under current clinical conventional static scoring criteria. 
Table 2. Specificity and sensitivity of pregnancy association with blastocyst timeliness.

\begin{tabular}{lccc}
\hline & Blastocyst formed: NO & $\begin{array}{l}\text { Blastocyst formed: YES } \\
\text { Pregnancy proven: NO }\end{array}$ & $\begin{array}{l}\text { Blastocyst formed: YES } \\
\text { Pregnancy proven: YES }\end{array}$ \\
\hline $\begin{array}{l}\text { Pregnancy proven: } \mathbf{n} / \mathbf{a} \\
\text { Timely cleavage } \\
\text { Total embryos }\end{array}$ & $\begin{array}{l}52 \text { (no embryo transfers) } \\
14 \text { (no embryo transfers) }\end{array}$ & $\begin{array}{c}7 \text { (true negatives, TN) } \\
78 \text { (false negatives, FN) } \\
66\end{array}$ & $\begin{array}{c}\text { 2 (false positives, FP) } \\
\text { (true positives, TP) } \\
28\end{array}$ \\
\hline
\end{tabular}

$\mathrm{SE}_{\mathrm{N} / \mathrm{T}}=\mathrm{TP} /(\mathrm{TP}+\mathrm{FN})=28 /(28+78)=0.26$

$S P_{N / T}=T N /(T N+F P)=8 /(8+0)=1.00$

Table 3. Specificity and sensitivity of correlation of untimeliness with blastocyst formation in cases of pregnancy failure.

\begin{tabular}{lcccc}
\hline $\mathbf{N = 1 8 0}$ & $\begin{array}{l}\text { No pregnancy: } \\
\text { Timely cleavage: } \text { any }\end{array}$ & $\begin{array}{l}\text { No pregnancy: } \\
\text { Untimely cleavage: }\end{array}$ & $\begin{array}{l}\text { YES } \\
\text { NO }\end{array}$ & $\begin{array}{l}\text { No pregnancy: } \\
\text { Untimely cleavage: }\end{array}$ YES \\
\hline $\begin{array}{l}\text { Blastocyst formed } \\
\text { Blastocyst not formed } \\
\text { Total embryos }\end{array}$ & 0 (no embryo transfers) & $\begin{array}{c}78 \text { (true negatives, TN) } \\
14 \text { (false negatives, FN) } \\
92\end{array}$ & $\begin{array}{c}5 \text { (false positives, FP) } \\
\text { (true positives, TP) } \\
60\end{array}$ \\
\hline
\end{tabular}

$\mathrm{SE}_{\mathrm{T} / \mathrm{B}}=\mathrm{TP} /(\mathrm{TP}+\mathrm{FN})=52 /(52+14)=0.78$

$\mathrm{SP}_{\mathrm{T} / \mathrm{B}}=\mathrm{TN} /(\mathrm{TN}+\mathrm{FP})=78 /(78+8)=0.90$

Table 4. Specificity and sensitivity of recognizing timely blastocysts yielding pregnancies.

\begin{tabular}{|c|c|c|c|}
\hline & Blastocyst formed: NO & Blastocyst formed: YES & Blastocyst formed: YES \\
\hline $\mathrm{N}=\mathbf{1 8 0}$ & Timely cleavage: any & Timely cleavage: NO & Timely cleavage: YES \\
\hline No pregnancy & 66 & 8 (true negatives, TN) & 78 (false positives, FP) \\
\hline Pregnancy proven & n/a (no embryo transfer) & 0 (false negatives, FN) & 28 (true positives, TP) \\
\hline Total embryos & 66 & 8 & 106 \\
\hline
\end{tabular}

$\mathrm{SE}_{\mathrm{BT} / \mathrm{P}}=\mathrm{TP} /(\mathrm{TP}+\mathrm{FN})=28 /(28+0)=1.00$

$\mathrm{SP}_{\mathrm{BT} / \mathrm{P}}=\mathrm{TN} /(\mathrm{TN}+\mathrm{FP})=8 /(8+78)=0.09$

Overall pregnancy predictivity is of a $100 \%$ specificity and neutral sensitivity

The diagnostic relation between the blastocyst nidation success and the cleavage timeliness (in this setup, the measure of a sorting tendency of pregnancyyielding blastocysts to fall within the timely cleavage group) was determined in Table 2 as being $100 \%$ specific, i.e., no pregnancy resulted from untimely blastocysts. Based on this result, impaired blastocysts (10\%) that appear morphologically normal but carry a hidden history of wrong, pregnancy-disfavoring course of cleavages that is never apparent in routine static observations, can be absolutely reliably excluded from intrauterine transfer simply by time-lapse monitoring. On the other side, the sensitivity (i.e., consorting exclusivity of pregnancies to occur in timely blastocysts only) was just $26 \%$, because timely blastocysts also contributed to failed embryo transfers. This $26 \%$ value is close to the average success of IVF cycles (Kiessling 2010), showing that mere timeliness of blastocysts is a single predictor of pregnancy not stronger than the average selection without time-lapse. This result is therefore in full concert with a general worldwide inability to recognize pregnancyyielding embryos among all high-quality embryos.

Moderate diagnostic value of blastocyst presence is refined with time-lapse data

Specificity of the relation between the blastocyst formation capability and the chronometric failure of notnidated embryos (i.e., the measure of a power to predict the unimplanted blastocysts by scoring their cleavage untimeliness), was about $90 \%$ according to Table 3 . In other words, $90 \%$ of all unimplanted blastocysts showed the same metrics as the blastocysts yielding pregnancies, 
thus ranking them among the embryos of the highest quality. This means that without knowing their time-lapse record, any embryos reaching the blastocyst stage do have a $90 \%$ chance of being timely cleaving, thus being functionally comparable to the embryos giving rise to pregnancies. Importantly, the remaining blastocysts with poor implantation potential $(10 \%)$ can be reliably recognized among other blastocysts based on their untimely cleavages, and discarded, based on the diagnostic time-lapse criteria addressed earlier in Table 2.

\section{Blastocyst-centered pregnancy prediction is $100 \%$} specific but remains insensitive

The final question was, how well embryo cleavage rating selects from all blastocysts for those that would surely nidate and yield clinical pregnancies. Based on Table 4 , the sensitivity was $100 \%$, i.e. all competent blastocysts were reliably selected for embryo transfers, with no unfavorably ranked blastocysts yielding any pregnancy. However, the specificity was quite low $(9 \%$ selectivity), because the majority of co-selected morphologically superior and timely cleaving blastocysts did not yield pregnancies. Thus, indicating that additional strong factors must occur after the blastocyst stage (and after the embryo transfer), which determine the future differences in final fates of those best, equally looking and equally behaving blastocysts, pre-selected by cleavage rating and morphology scoring.

\section{Conclusions}

Embryo cleavage rating, a novel method based on time-lapse imaging, has a strong selective power for the highest-quality embryos to be selected for embryo transfer. This power increases with the number of rated cell cycles, reaching the maximum when concluded on 5th day with the blastocyst formation assessment. Additionally, evanescent transitory post-mitotic changes in embryonic cell numbers can only be uncovered by time-lapse imaging ("filming") of embryos, where conventional static observations fail. However, our ability to identify exactly the blastocysts that will yield pregnancies among all blastocysts remains yet unresolved. Nevertheless, it can be concluded that timelapse-based cleavage rating effectively contributes to the closest demarcation of the narrowest possible group of good-looking and well-proliferating embryos, whose implantation failures are stemming exclusively from postblastocyst-stage-manifested phenotypical features, or are embryo-independent (maternal, etc.).

\section{Discussion}

In current clinical human assisted reproduction, many different selection criteria are used as a means of selecting the assumed most viable embryos for transfer into the uterus. The transfer of single embryo with the highest implantation potential would be an ideal strategy to avoid multiple pregnancies presenting a health hazard to the mother as well as to children. For the purposes of postulation of appropriate selection markers for humanmeans and computer-assisted embryonic diagnosis, we focused on the earliest developmental phases of the embryonic development on the grounds of the prior evidence that early scoring parameters are strong positive predictors of implantation (Scott et al. 2007).

\section{Contextual relation to other studies}

Our former preliminary results (Dudas et al. 2009, Hlinka et al. 2010) had suggested a correlation between embryonic health and mitotic timing. This relation was very recently reconfirmed by a concurrent work of others (Kiessling 2010, Meseguer et al. 2011, Pribenszky et al. 2010, Wong et al. 2010), while infrequent studies were mentioning chronometric observations in various biological contexts and mammalian species for decades ago (Arav et al. 2008, Barrenas et al. 2000, Brezinova et al. 2009, Ebner et al. 2003, Fenwick et al. 2002, Lequarre et al. 2003, Lundin et al. 2001, Magli et al. 2007, Racowsky et al. 2000, Roux et al. 1995, Sakkas et al. 1998, Van Soom et al. 1997). Previous studies were often hampered by a lack of high-throughput scoring, low automation, or inavailability of large human embryo cohorts to be observed for several days. Therefore, this study aimed at a very systematic and extremely precise automated capture of all mitotic events, all interphases, and all blastomere numbers, this all at dense sampling pace of 10-minute steps, and during the entire duration of three complete and consecutive cell cycles, with the extended observation until the blastocyst stage up to 5 days, in 180 embryos of human origin, under real clinical IVF setup, and with clinical verification of the resulting pregnancies.

\section{Approximations in measuring the duration of interphases}

As defined in Methods, each approximated embryonic interphase interval starts when all blastomeres have finished their cleavages within the previous cell cycle, and ends when the first blastomere cleaves in the observed (current) cell cycle. The initial interphase 
measured in this study was the interval i2, meaning the approximated interphase of the second embryonic cell cycle, defined shortly in other words as the 2-cell period (i.e., starting from the time point immediately after the zygotic 1st cleavage was resumed and the two daughter blastomeres were separated, until the earliest next cleavage was detected in one of these twin blastomeres). Analogically, i3 was measured as the 4-cell time period until 5 cells, and i4 during the 8-cell stage until 9 cells in normally cleaving embryos.

In essence, this definition means that each approximated interphase interval does not precisely reflect the duration of the interphase of any given single blastomere, but instead, it provides a global information on cleavage activity of the embryo as a whole. Inherently, such approximated interphase interval comprises the resting (non-cleaving) portion of the studied embryonic mitotic cycle, together with the initial fragment of time factually belonging to the subsequent new cell cycle (i.e., the M-phase of the first-cleaving blastomere of the new cell cycle, while the other blastomeres are still resting). On the other hand, another fragment of the resting time is virtually missing from the beginning of each approximated interphase interval (i.e., the time from the end of cleavage of the first-cleaving blastomere, which starts resting while other blastomeres cleave, till the end of cleavage of the last-cleaving blastomere). Overall, the time loss at the beginning is roughly compensated by the time gain at the end of each approximated interphase interval (which is anyway measured quite crudely considering that the time-lapse step is $10 \mathrm{~min}$ ). Such approximation (formalization) was necessary and specifically useful for the present study, because it was not possible to detect cells exiting the G2 phase and entering the M-phase in other means; the only events that can be reliably detected by time-lapse instruments are cell divisions, and therefore, this study adheres to cell divisions being the major timing landmarks.

\section{Specific features of the first cell cycle}

The first interphase (i1) would match the zygotic stage, i.e. 1-cell stage spanning from the moment of fertilization till the moment of the completion of the first cleavage. Since there is only a single cell that is cleaving in the zygote, it is basically impossible to separate the zygotic interphase (i1) from the zygotic M-phase, thus making the distinction of the $\mathrm{c} 1$ interval practically impossible in the context of current time-lapse instruments. It is important to note that the intervals i1 and $\mathrm{c} 1$ were not scored in our present experimental study, and the above mentioned was one of the reasons.

In general, the total time from fertilization to $1 \mathrm{st}$ division is measurable. Interestingly, human embryos which cleave early, i.e. complete the first mitotic division within 25-27 $\mathrm{h}$ after insemination, provide higher pregnancy and implantation rates (Lundin et al. 2001). However, interpreting the first cell cycle duration and its clinical relevance is often hampered by common difficulties that are related to the biology of fertilization and the zygote, involving multiple molecular variables and extensive phenotypic variation. Fertilization is a multi-step process involving the oocyte penetration by the sperm cell, oocyte activation, reorganization of the male chromatin, pronuclei formation, and establishment of the 1-cell embryo ready to start mitotic divisions. Normal human zygotes undergo the first cleavage divison at 24 $27 \mathrm{~h}$ after fertilization (Fenwick et al. 2002, Lundin et al. 2001). Although the reasons for the observed variation in the timing of the first zygotic cleavage are still not clear (Plachot 2000), they may be related to culture conditions and some intrinsic factors within the oocyte and/or sperm such as ooplasm volume and maturity, differences in the ability of individual spermatozoa to modulate calcium metabolism, paternal effects on the duration of the Sphase, or chromosomal abnormalities and DNA repair processes. It was shown in humans that the timing of the first zygotic cleavage is not influenced either by the timing of fertilization nor by semen parameters (Sakkas et al. 1998). As most time-lapse systems that have been introduced clinically acquire images every 10-20 min, it would be difficult to obtain and evaluate in detail any parameters occurring before the first cleavage. The detailed analysis of the events before 1st division would be enabled by short intervals (about 1-5 min) and using elaborate contrast methods.

\section{Approximations in measuring the duration of cleavages}

The cleavage clusters defined in this study are basically the time periods remaining after subtracting interphase intervals from the total time-lapse monitoring time. In real life, post-interphase cleavages of corresponding sister blastomeres seldom occur at precisely the same second, therefore the durations of the wave (cluster) of cleavages following each of the interphases was measured from the end of the first till the end of the last cleavage in any given cleavage cluster (i.e., c 2 being between 3 and 4 cells, c 3 between 5 and 8 , and $\mathrm{c} 4$ between 9 and 16 cells; see Table 1 and Figs 2, 4). 
This way, no time was omitted nor overlapping in the assessment of the continuum of alternating interphases and cleavages (i2-c2-i3-c3-i4-c4).

\section{Clinical practicality}

Under a typical setup in clinical IVF laboratories, where hundreds of embryos may be nursed at any moment, eyeing of embryos once or a few times a day is considered sufficient according to contemporary guidelines and regulations. In addition, certain procedures such as repeated embryo freezing or oocyte banking (Chang et al. 2008) may represent an increased or yet unknown risk for mitotic errors, where detailed monitoring would be beneficial. Human-made reading of each embryo's status every $10 \mathrm{~min}$ is simply impossible due to speed limitations of manual handling and eyebased scoring, not even mentioning that $\mathrm{CO}_{2}$ incubators would be longer open than closed and embryos would encounter very inconsistent gas and temperature conditions. On the other side, numerous small microscopy automates can be placed directly in incubators, allowing for simultaneous monitoring of many embryos, with an additional benefit of all embryos dwelling still and not being rotated due to agitations caused inevitably by any manual handling. From the aspect of clinical practicality, we did not identify any significant technical or practical limitations or obstacles associated with time-lapse imaging.

\section{Relativity of diagnostic power}

This study classifies embryos according to their mitotic behavior into two categories (timely and untimely cleaving). The design-related limitation of our study is the definition of these two classes, which was arbitrarily derived from the chronometric values of the blastocysts that yielded clinical pregnancies. The entire range of interphase and cleavage durations in these successful blastocysts was considered "timely" (normal), whereas any deviation was considered "untimely". Methodologically, there is nothing erroneous with a justified derivation of the internal standards from within the subset of the statistical cohort per se, but such introspective normalization and conjoined recursivity in all subsequent statistical computations partly precludes direct comparison of our data with any subsequent studies by other groups. In other words, since the normal distribution of mitotic event durations may vary from laboratory to laboratory, our reference values for cleavage durations may not be generally valid as worldwide standards for embryo classification - and presumably the best practice would be that each team shall determine a new set of their own normalized reference values. Nowadays, it can only be speculated whether different formulations of culture media and fluctuations in cultivation conditions of incubators worldwide will or will not result in changes of mitotic timing data. This problem shall be addressed in future by meta-analysis; for now, setting own internal standards by each research group seems to be a reasonable recommendation.

\section{Selection against gross developmental anomalies is redundant}

Although the Fig. 1 demonstrates a clear clustering of abnormally shaped embryos in the group of untimely cleaving, and despite that our scoring system used in this study allowed for their exclusion from embryo transfers with $100 \%$ precision, we conclude that time-lapse analysis did not deliver any improvement into this particular aspect of preimplantation diagnosis. Obvious morphological anomalies and growth retardation can be equally well recognized by mere conventional daily static observations.

\section{Unique time-lapse selection features}

On the other hand, our time-lapse records had uncovered novel scoring markers and formerly unrecognized contexts of previously known morphometric signs. For instance, early appearance of new blastomeres may not be a good sign of expedited embryonic proliferation sensu early cleavage (Arav et al. 2008, Sakkas et al. 1998, Scott et al. 2007), but a result of abnormal hypernumerary cleavage (Figs 2, 3). This is an explanation consistent with earlier observations of a puzzling biological phenomenon that uneven embryonic cell numbers at day 2 were unfavorable in terms of IVF outcomes, for which the reasons were originally sought in different mitotic speed or embryonic polarity (Scott et al. 2007). In our records, some embryos formed 5 cells (instead of normal 4 cells) after abnormal second mitotic cleavage, i.e. approximately $36 \mathrm{~h}$ after ICSI (the morning of day 2). This has been revealed as a result of producing of 3 cells from one blastomere of the two cell stage embryo, while the second cell divided normally to two daughter cells ("c2b5" embryos from Fig. 2). Such embryos are morphologically indistinguishable from normal 5-cell embryos. Normally, the 5-cell stage is adequate at the beginning of the third mitotic division 
(usually expected in the afternoon of the day 2), and the third mitosis gradually produces 5-, 6-, 7-, and finally 8cell embryos in a single cleavage cluster within a very short time (Figs 1,2). Due to a normal variability in cell cycle duration ( 6 hours and 2 hours for interphases 1 and 2 , respectively), and with additional technical variability introduced by different moments of spontaneous fertilization or ICSI, cultured embryos of a corresponding fertilization age may be developmentally apart from each other by 8 or even more hours. Without time-lapse recording, it would not be practically feasible to tell apart the c2b5 embryos from normal embryos at the beginning of their c3 (cleavage 3).

\section{Possible implications of hypercellular cleavage diagnosis} Embryos containing surplus blastomeres (e.g., those denoted as c1b3>2 and c2b5 embryos in Fig. 2) are two real examples with documented cleavage abnormality but with confusingly normal visual appearance. Both examples were identified among mere 180 embryos recorded in our very first pilot study. Thus, suggesting that the number of similar cryptic anomalies will soon increase with subsequent observations in various laboratories worldwide. We speculate that these seemingly well developing embryos might be predominantly composed of a mixture of aneuploid and euploid cells, thus forming mosaic embryos, in opposite to timely and evenly cleaving embryos that are anticipated to contain evenly constituted blastomeres. This must be proven by multicentric studies in a large cohort of embryos (a long-term genetic study addressing this hypothesis was already started in our laboratories). Although this is just a hypothesis at this time, the hypercellular embryos are definitely already worth of being considered a developmental anomaly that cannot be revealed by conventional daily embryo assessment in IVF clinics. Thus, their exclusion from clinical usage based on time-lapse analysis could save resources and time wasted if these unviable embryos were used for embryo transfers and/or blastomere biopsy.

\section{Perspectives}

Opportunities for detailed morphological observations of developing embryos are far from being exhausted. Innovative techniques like continuous embryo monitoring, combinations of various contrast microscopy imaging modes and timing series, three-dimensional analysis, detection of cell relocations, analysis of videos, or study of cytoskeleton polarity can reveal a completely new knowledge. For example, fertilized oocytes are the first totipotent cells and exhibit calcium oscillations (Kupker et al. 1998) that can be displayed and analyzed by cybernetic techniques; in addition, patch-clamp technique is routinely used in microscopic electrophysiology (Karmazinova and Lacinova 2010, Ye 2010) that could be easily adopted for embryological research. Moreover, the hormonal status of the mother influences the child, while also vice versa, the child affects a pregnant woman (Hill et al. 2010, Koskova et al. 2009). Thus, it is anticipated that embryonic diagnosis in future will also be used to predict the hormonal activity of the embryo and perhaps its impact on mother's health status. Out of the field of fertility, evaluation of embryo viability is also a cornerstone procedure for obtaining stem cells for the biotechnological industry, such as tissue engineering (Vagaska et al. 2010). All these analyses can become a part of experimental image analysis and diagnostics of oocytes and blastomeres in the nearest future. However, for clinical practice, noninvasive, quick, and high-throughput methods are preferred. In this context, contactless time-lapse monitoring described in this work is currently a method of choice.

\section{Concluding Points}

In summary, detailed time-lapse monitoring paced at 10-minute intervals has been demonstrated to effectively select against unviable embryos (including the functionally / mitotically deviant but morphologically normal embryos), which are the most suspected cause of frequent IVF failures such as nidation failure or early abortion. Non-invasive embryo cleavage rating (ECR) is a strong candidate to supplement invasive aneuploidy tests based on blastomere biopsy, which are inherently prone to unavoidable diagnostic errors caused by uneven chromosome contents in individual blastomeres (mosaicism). ECR could pre-select the best-cleaving embryos before blastomere biopsy, thus reducing the diagnostic time and resources. ECR can also be used as a standalone contact-free and non-invasive scoring system, if other diagnostic modalities are unavailable or unacceptable for IVF patients. Even without the usage of automated equipment, cleavage timeliness can be approximately assessed as shown in the simplified summary Fig. 4. 


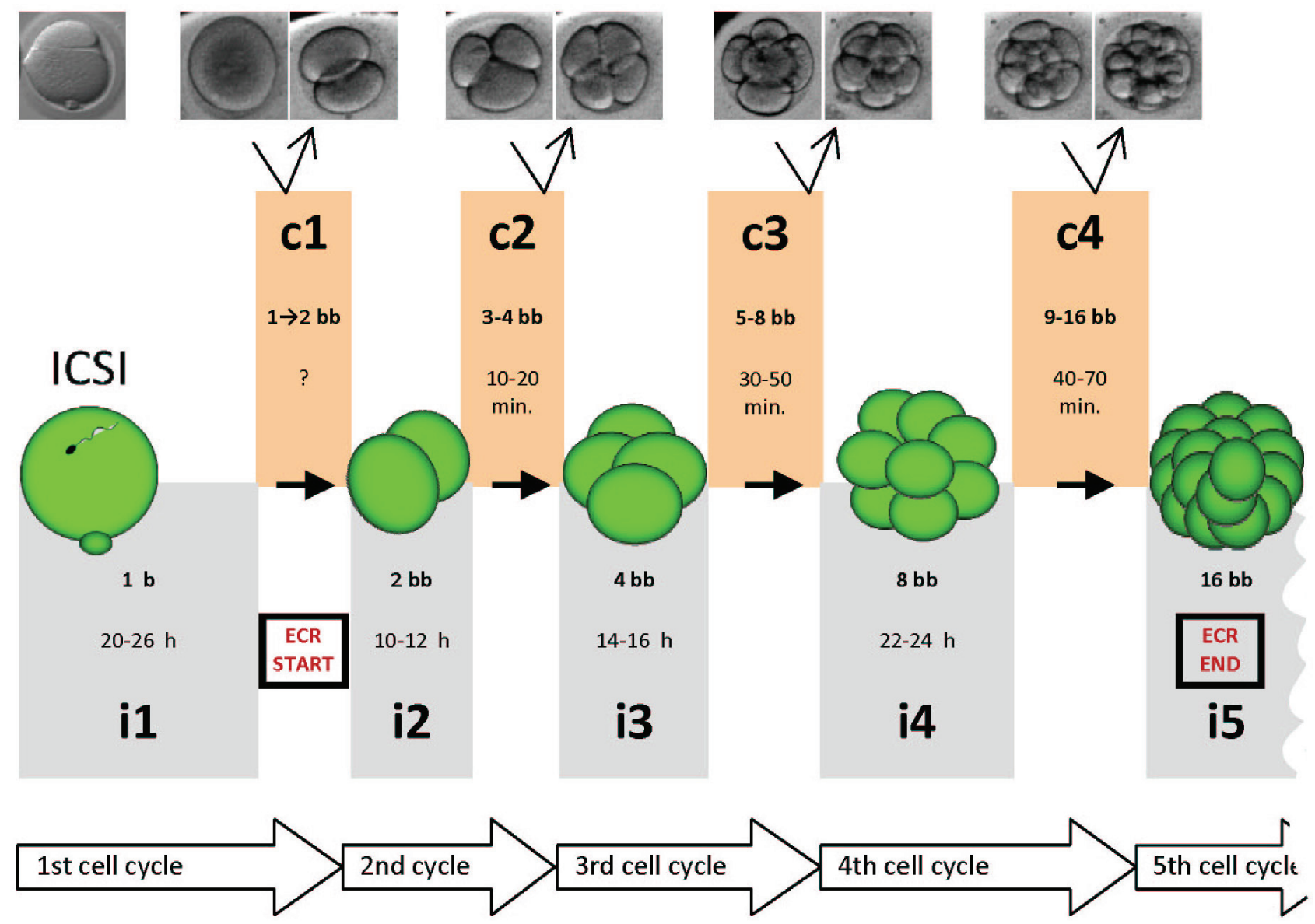

Fig. 4. Simplified correlation of major scoring points in embryo cleavage rating (ECR) with cell cycles and photographs of corresponding developmental stages. Please see Discussion for difficulties with separating i1 from c1. c1 to c4-approximated cleavages of the cell cycles 1 to 4 ; i1 to i5 - approximated interphases of the cell cycles 1 to 5; $\mathbf{b} \mathbf{b}$ - number of blastomeres.

\section{Conflict of Interest}

There is no conflict of interest.

\section{Acknowledgements}

This research was supported by resources of the first author's (DH) private clinic and by competitive academic grants of the senior author (MD): MZ SR 2007/65-UPJS02, APVV-0682-07, ASFEU ITMS NFP-26220120024 \& NFP-26220120039, APVV VVCE-0001-07, and VEGA 1/0501/10. We thank M. Falisova and I. Benova for technical assistance.

\section{References}

ARAV A, AROYO A, YAVIN S, ROTH Z: Prediction of embryonic developmental competence by time-lapse observation and 'shortest-half' analysis. Reprod Biomed Online 17: 669-675, 2008.

BARRENÄS M, LANDIN-WILHELMSEN K, HANSON C: Ear and hearing in relation to genotype and growth in Turner syndrome. Hear Res 144: 21-28, 2000.

BASILLE C, FRYDMAN R, EL ALY A, HESTERS L, FANCHIN R, TACHDJIAN G, STEFFAN J, LELORCH M, ACHOUR-FRYDMAN N: Preimplantation genetic diagnosis: state of the art. Eur J Obstet Gynecol Reprod Biol 145: 9-13, 2009.

BEUCHAT A, THEVENAZ P, UNSER M, EBNER T, SENN A, URNER F, GERMOND M, SORZANO CO: Quantitative morphometrical characterization of human pronuclear zygotes. Hum Reprod 23: 1983-1992, 2008.

BREZINOVA J, OBORNA I, SVOBODOVA M, FINGEROVA H: Evaluation of day one embryo quality and IVF outcome - a comparison of two scoring systems. Reprod Biol Endocrinol 3: 7-9, 2009. 
CHANG CC, SHAPIRO DB, BERNAL DP, WRIGHT G, KORT HI, ZSOLTNAGY P: Two successful pregnancies obtained following oocyte vitrification and embryo re-vitrification. Reprod. Biomed Online 16: 346-349, 2008.

DANKOVCIK R, CISARIK F, GRESOVA A, LAZAR I, URDZIK P: Antenatal screening of chromosomal abnormalities. (in Slovak) Gynekol Prax 3: 147-151, 2005.

DUDAS M, HLINKA D, DANKOVCIK R, TOMORI Z: Combining novel experimental and bioinformatic tools for the advancement of preimplantation genetic diagnosis. In: Reproductive Medicine - Presence and Perspectives. (in Czech) OSTRO A, PILKA L, LESNIK F (eds), Nakladatelství Olomouc, Olomouc, 2009, pp 176-194.

EBNER T, MOSER M, SOMMERGRUBER M, TEWS G: Selection based on morphological assessment of oocytes and embryos at different stages of preimplantation development: a review. Hum Reprod Update 9: 251-262, 2003.

FENWICK J, PLATTEAU P, MURDOCH AP, HERBERT M: Time from insemination to first cleavage predicts developmental competence of human preimplantation embryos in vitro. Hum Reprod 17: 407-412, 2002.

GARDNER DK, VELLA P, LANE M, WAGLEY L, SCHLENKER T, SCHOOLCRAFT WB: Culture and transfer of human blastocysts increases implantation rates and reduces the need for multiple embryo transfers. Fertil Steril 69: 84-88, 1998.

GARELLO C, BAKER H, RAI J, MONTGOMERY S, WILSON P, KENNEDY CR, HARTSHORNE GM: Pronuclear orientation, polar body placement, and embryo quality after intracytoplasmic sperm injection and in-vitro fertilization: further evidence for polarity in human oocytes? Hum Reprod 14: 2588-2595, 1999.

GIANAROLI L, MAGLI MC, FERRARETTI AP, FORTINI D, GRIECO N: Pronuclear morphology and chromosomal abnormalities as scoring criteria for embryo selection. Fertil Steril 80: 341-349, 2003.

HERNANDEZ ER: What next for preimplantation genetic screening? Beyond aneuploidy. Hum Reprod 24: 1538-1541, 2009.

HILL MA, PARIZEK A, JIRASEK JE, JIRKOVSKA M, VELIKOVA M, DUSKOVA M, KLIMKOVA M, PASKOVA A, ZIZKA Z, GERMANOVA A, KOUCKY M, KALOUSOVA M, STARKA L: Is maternal progesterone actually independent of the fetal steroids? Physiol Res 59: 211-224, 2010.

HLINKA D, DUDAS M, HERMAN M, KALINA I: Experimental attempts to extend the current preimplantation genetic diagnosis with individual karyotypization of human blastomeres. Reprod Nutr Dev 41: 91-106, 2001.

HLINKA D, DUDAS M, RUTAROVA J, REZACOVA J, LAZAROVSKA S: Permanent embryo monitoring and exact timing of early cleavages allow reliable prediction of human embryo viability. Hum Reprod $\mathbf{2 5}$ (Suppl 1): i170i210, 2010.

KARMAZINOVA M, LACINOVA L: Measurement of cellular excitability by whole cell patch clamp technique. Physiol Res 59 (Suppl 1): S1-S7, 2010.

KIESSLING A: Timing is everything in the human embryo. Nature Biotechnol 28: 1025-1026, 2010.

KILANI S, COOKE S, KAN A, CHAPMAN M: Are there non-invasive markers in human oocytes that can predict pregnancy outcome? Reprod Biomed Online 18: 674-680, 2009.

KOSKOVA I, PETRASEK R, VONDRA K, DUSKOVA M, STARKA L: Metabolic profile and sex hormone binding globulin (SHBG) in different reproductive phases of Czech women and their relations to weight, body composition and fat distribution. Physiol Res 58: 393-402, 2009.

KUPKER W, DIEDRICH K, EDWARDS RG: Principles of mammalian fertilization. Hum Reprod 13: 20-32, 1998.

LEQUARRE AS, MARCHANDISE J, MOREAU B, MASSIP A, DONNAY I: Cell cycle duration at the time of maternal zygotic transition for in vitro produced bovine embryos: effect of oxygen tension and transcription inhibition. Biol Reprod 69: 1707-1713, 2003.

LOS FJ, VAN OPSTAL D, VAN DEN BERG C: The development of cytogenetically normal, abnormal and mosaic embryos: a theoretical model. Hum Reprod Update 10: 79-94, 2004.

LUNDIN K, BERGH C, HARDARSON T: Early embryo cleavage is a strong indicator of embryo quality in human IVF. Hum Reprod 16: 2652-2657, 2001.

MAGLI MC, GIANAROLI L, FERRARETTI AP, LAPPI M, RUBERTI A, FARFALLI V: Embryo morphology and development are dependent on the chromosomal complement. Fertil Steril 87: 534-541, 2007.

MESEGUER M, HERRERO J, TEJERA A, HILLIGSOE KM, RAMSING NB, REMOHI J: The use of morphokinetics as a predictor of embryo implantation. Hum Reprod 26: 2658-2671, 2011. 
MURBER A, FANCOVITS P, LEDO N, GILAN ZT, RIGO J, URBANCESEK J: Impact of GnRH analogues on oocyte/embryo quality and embryo development in in vitro fertilization/intracytoplasmic sperm injection cycles: a case control study. Reprod Biol Endocrinol 7: 103, 2009.

PATON GR, SILVER MF, ALLISON AC: Comparison of cell cycle time in normal and trisomic cells. Humangenetik 23: 173-182, 1974.

PLACHOT M: Fertilization. Hum Reprod 15: 19-30, 2000.

PRIBENSZKY C, MATYAS S, KOVACS P, LOSONCZI E, ZADORI J, VAJTA G: Pregnancy achieved by transfer of a single blastocyst selected by time-lapse monitoring. Reprod Biomed Online 21: 533-536, 2010.

RACOWSKY C, JACKSON KV, CEKLENIAK NA, FOX JH, HORNSTEIN MD, GINSBURG ES: The number of eight-cell embryos is a key determinant for selecting day 3 or day 5 transfer. Fertil Steril 73: 558-564, 2000.

ROUX C, JOANNE C, AGNACI G, FROMM M, CLAVEQUIN MC, BRESSON JL: Morphometric parameters of living human in-vitro fertilized embryos: importance of the asynchronous division process. Hum Reprod 10: 1201-1207, 1995.

SAKKAS D, SHOUKIR Y, CHARDONNENS D, BIANCHI PG, CAMPANA A: Early cleavage of human embryos to the two-cell stage after intracytoplasmic sperm injection as an indicator of embryo viability. Hum Reprod 13: 182-187, 1998.

SCOTT L, FINN A, O'LEARY T, MCLELLAN S, HILL J: Morphologic parameters of early cleavage-stage embryos that correlate with fetal development and delivery: prospective and applied data for increased pregnancy rates. Hum Reprod 22: 230-240, 2007.

SHAHINE LK, CEDARS MI: Preimplantation genetic diagnosis does not increase pregnancy rates in patients at risk for aneuploidy. Fertil Steril 85: 51-56, 2006.

VAGASKA B, BACAKOVA L, FILOVA E, BALIK K: Osteogenic cells on bio-inspired materials for bone tissue engineering. Physiol Res 59: 309-322, 2010.

VAN BLERKOM J, DAVIS P, MATHWIG V, ALEXANDER S: Domains of high-polarized and low-polarized mitochondria may occur in mouse and human oocytes and early embryos. Hum Reprod 17: 393-406, 2002.

VAN SOOM A, YSEBAERT MT, DE KRUIF A: Relationship between timing of development, morula morphology, and cell allocation to inner cell mass and trophectoderm in in vitro produced bovine embryos. Mol Reprod Dev 47: 47-56, 1997.

YE B: $\mathrm{Ca}^{2+}$ oscillations and its transporters in mesenchymal stem cells. Physiol Res 59: 323-329, 2010.

WONG CC, LOEWKE KE, BOSSERT NL, BEHR B, DE JONGE CJ, BAER TM, REIJO PERA RA: Non-invasive imaging of human embryos before embryonic genome activation predicts development to the blastocyst stage. Nature Biotechnol 28: 1115-1121, 2010. 